\title{
VERSITA
}
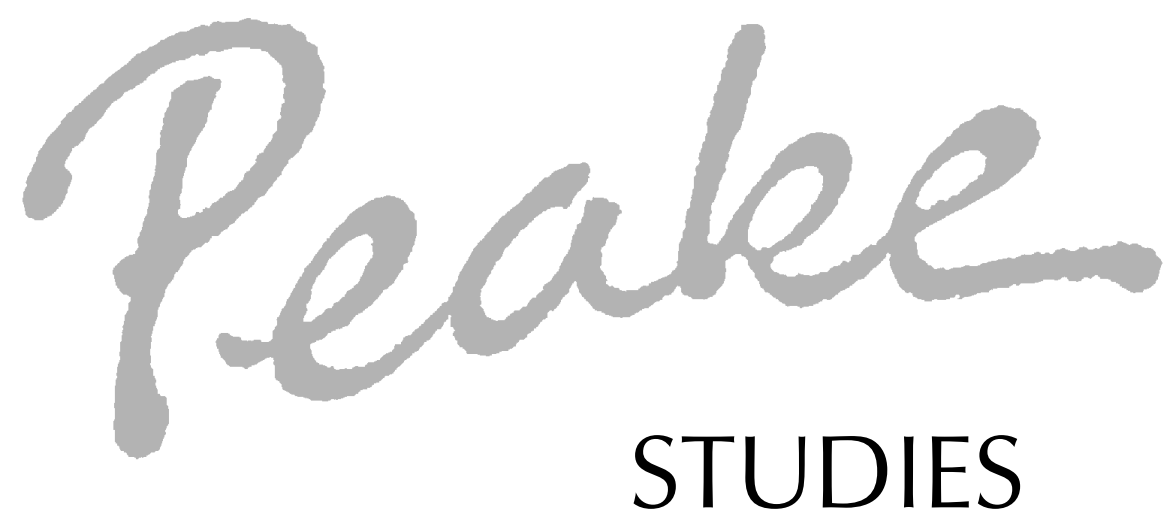

\section{Vol. 13, no 2}

April 2013

Unless otherwise indicated, the contents of Peake STUDIES are (C) G Peter Winnington 2013.

Acknowledgement is made to the Mervyn Peake Estate for permission to reproduce Mervyn Peake's words and images. Unless otherwise indicated the previously unpublished works by Mervyn Peake in this issue are (C) the Mervyn Peake Estate 20I3.

Edited and published by G Peter Winnington, 2 ch du Collège, I 453 Mauborget, Switzerland.

Tel. +4I 244362232 E-mail peakestudies@gmail.com Home page http://peakestudies.com 


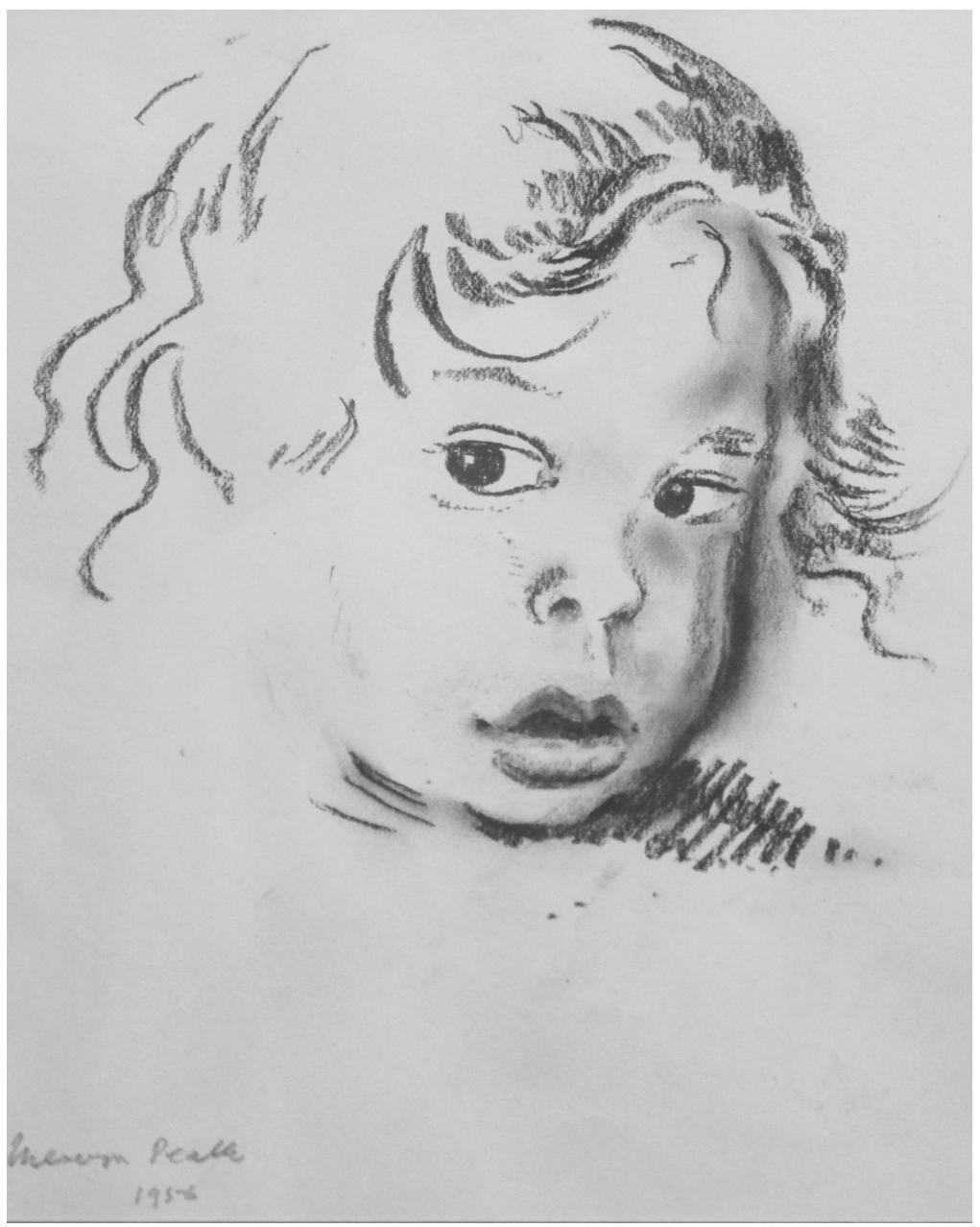

Portrait (possibly of Clare) in brown crayon on paper,

$11 \times 9$ inches, signed and dated 1956 in pencil. (Image kindly supplied by Mike Kemp.) 